International Journal of Maternal and Child Health and AIDS (202I), Volume I0, Issue I, 43-54

\begin{tabular}{ll}
\hline & INTERNATIONAL JOURNAL of \\
& MATERNAL and CHILD HEALTH and AIDS \\
& ISSN 216I-864X (Online) \\
& ISSN 216I-8674 (Print) \\
IJMA Available online at www.mchandaids.org & DOI: 10.21 I 06 /ijma.448 \\
\hline
\end{tabular}

\title{
ORIGINAL ARTICLE | MATERNAL MORTALITY \\ Trends and Racial/Ethnic, Socioeconomic, and Geographic Disparities in Maternal Mortality from Indirect Obstetric Causes in the United States, 1999-20I7
}

\author{
Gopal K. Singh, PhD, MS, MSc; ${ }^{1 \otimes}$ Hyunjung Lee, PhD, MS, MPP, MBA $A^{1,2}$ \\ 'US Department of Health and Human Services, Health Resources and Services Administration Office of Health Equity, 5600 Fishers Lane, Rockville, MD \\ 20857, USA; ${ }^{2}$ Oak Ridge Institute for Science and Education (ORISE), TN 3783I, USA \\ Corresponding author e-mail: gsingh@hrsa.gov
}

\begin{abstract}
Background: This study examines trends and inequalities in US maternal mortality from indirect obstetric causes (ICD-10 codes: O98-O99) and specific chronic conditions by maternal race/ethnicity, socioeconomic status, nativity/immigrant status, marital status, place and region of residence, and cause of death.

Methods: National vital statistics data from 1999 to 2017 were used to compute maternal mortality rates by sociodemographic factors. Rate ratios and log-linear regression were used to model mortality trends and differentials.

Results: During 1999-2017, maternal mortality from indirect causes showed an upward trend; the annual rates increased by II .2\% for the overall population, I $2.9 \%$ for non-Hispanic Whites, and $9.4 \%$ for non-Hispanic Blacks. The proportion of all maternal deaths due to indirect causes increased from $12.0 \%$ in 1999 to $26.9 \%$ in 2017. Maternal mortality from CVD increased sharply over time, from 0.40/100,000 live births in 1999 to 1.82 in 2017. During 2013-20I7, compared to non-Hispanic Whites, non-Hispanic Blacks had $83 \%$ higher, Hispanics $51 \%$ lower, and Asian/Pacific Islanders 55\% lower mortality from indirect causes. Non-Hispanic White women with $<12$ years of education had 4.4 times higher mortality than those with a college degree. Unmarried, US-born, and women living in rural areas and deprived areas had $90 \%, 80 \%, 60 \%$, and $97 \%$ higher maternal mortality risks than married, immigrant, and women in urban areas and affluent areas, respectively. Maternal mortality from infectious diseases, including HIV, was 4.I times greater and from respiratory diseases 2.9 greater among non-Hispanic Black women compared to non-Hispanic White women.

Conclusions and Global Health Implications: While maternal mortality from direct obstetric causes has declined during the past two decades, maternal deaths due to indirect causes, particularly from preexisting medical conditions, including CVD and metabolic disorders, have increased. Understanding complex interactions among social determinants, indirect causes, and proximate/direct causes is important to reducing maternal mortality and improving maternal health.
\end{abstract}

Key words: • Maternal mortality • Socioeconomic status • Deprivation • Race/ethnicity • Rural-urban • Disparities • Cause of death $\bullet$ Trend

Copyright $($ C 2021 Singh and Lee. Published by Global Health and Education Projects, Inc. This is an open-access article distributed under the terms of the Creative Commons Attribution License CC BY 4.0 . 


\section{Introduction}

Although the leading causes of maternal deaths in the United States are hemorrhage, pregnancyrelated hypertension, embolism, and obstetric infection, maternal deaths due to indirect obstetric causes, including chronic medical conditions such as cardiovascular disease (CVD), diabetes, respiratory disorders, and mental health conditions, have increased substantially in the past two decades., ${ }^{1,2}$ Globally, including the United States, $25-30 \%$ of all maternal deaths are attributed to these indirect causes. ${ }^{3-5}$ Recent trends and socioeconomic and demographic disparities in US maternal mortality from indirect causes have not been well studied, although the proportionate share of various indirect causes to overall mortality and racial/ethnic patterns have been examined using death certificate-based maternal mortality and Pregnancy Mortality Surveillance System data. ${ }^{6-9}$ To our knowledge, none of the US studies have analyzed inequalities in maternal mortality from indirect causes by a wide range of social determinants, including maternal education, marital status, nativity/immigrant status, place of residence, geographic region, and area deprivation. Analyzing disparities according to these social determinants is important in identifying sociodemographic groups and disadvantaged communities that may be at increased risk of maternal morbidity and mortality and which can benefit from targeted social and public heath interventions.

To address the aforementioned gaps in research, we analyzed racial/ethnic, socioeconomic, demographic, rural-urban, and regional variations in US maternal mortality from indirect obstetric causes and specific chronic conditions (ICD-I0 codes 098-099) occurring during or within 42 days after the end of pregnancy. ${ }^{1,2,10}$

\section{Methods}

We used 1999-2017 data from the National Vital Statistics System, the national mortality database. 1,2,10 Maternal deaths in this study, are defined in accordance with the $\mathrm{WHO}$ as those related to or aggravated by pregnancy or pregnancy management and which occur during or within 42 days after the end of pregnancy. ${ }^{1,2,10}$ This official definition of maternal mortality differs from the definition of pregnancy-related mortality, which includes deaths during or within I year of pregnancy. 8,9

Rates of maternal mortality from indirect causes were computed annually between 1999 and 2017 for all races, Whites and Blacks. Maternal deaths and rates for Asian and Pacific Islanders (APIs),American Indians and Alaska Natives (AIANs) and Hispanics, maternal education, marital status, nativity/immigrant status, and maternal age were derived using the pooled 5-year mortality and natality data for the period 2013-2017 because of the small numbers of maternal deaths annually and to produce statistically robust estimates for these demographic groups. The numbers of births by these sociodemographic characteristics, obtained from the national natality files, served as the denominators for computing maternal mortality rates."

Area-based socioeconomic patterns in maternal mortality were derived by linking the 2008-2012 census-based county-level deprivation index to the race- and county-specific mortality statistics from 2013 to 2017.12-15 We used previously developed factor-based area deprivation index (ADI), developed by Singh and colleagues, using data from the 2008-20I 2 American Community Survey. ${ }^{12-15}$ The ADI consisted of 21 census-based socioeconomic indicators, which may be viewed as broadly representing educational opportunities, labor force skills, economic, and housing conditions in a given county. ${ }^{12-15}$ Selected indicators of education, occupation, wealth, income distribution, unemployment rate, poverty rate, and housing quality were used to construct these indices by factor and principal components analyses. ${ }^{12-15}$ The factor loadings (correlations of indicators with the ADI) for the 2008-20I 2 county index varied from 0.91 for $150 \%$ of the poverty rate to 0.23 for home ownership rate. ${ }^{12,15}$ To compute maternal mortality rates by deprivation level, we used the weighted population quintile distribution of the deprivation index that classified all $3,|4|$ US counties into 5 groups of approximately equal population size. ${ }^{12-}$ 15 The groups thus created ranged from being the most-deprived (first quintile) to the leastdisadvantaged (fifth quintile) population groups. ${ }^{12-15}$ To simplify analysis and for statistical robustness, we 
combined 2nd, 3rd, and 4th quintiles as the middle deprivation category. Each of the 3,I4I counties in the mortality database was assigned one of these 3 deprivation quintiles.

Log-linear regression models were used to estimate annual rates of change in maternal mortality from indirect causes. ${ }^{13-15}$ Specifically, the logarithm of mortality rates were modeled as a linear function of time (calendar year), which yielded annual exponential rates of change in mortality rates. ${ }^{13-15}$ Disparities in mortality by social factors and deprivation level were described by rate ratios (relative risks $=\mathrm{RR}$ ) and rate differences (absolute inequalities), which were tested for statistical significance at the 0.05 level.

\section{Results}

\section{I. Trends in Maternal Mortality from Indirect Causes}

Maternal mortality from indirect causes showed an upward trend during 1999-2017, with the rate increasing by $1 \mathrm{I} .2 \%$ (95\% Cl=9.0\%-13.5\%) annually for the overall population, $12.9 \%(95 \% \mathrm{Cl}=10.5 \%-$ 15.3\%) for non-Hispanic Whites, and 9.4\% (95\% $\mathrm{Cl}=7.2 \%-\mathrm{II} .6 \%$ ) for non-Hispanic Blacks (Figure I). During 1999-2017, non-Hispanic Black women had 2-3 times higher mortality from indirect causes than non-Hispanic White women. The proportion of all maternal deaths due to indirect causes rose from $12.0 \%$ in 1999 to $26.9 \%$ in 2017 (Figure 2). Of I2, I35 maternal deaths that occurred during 1999-2017, 3184 deaths were from indirect causes, including 173 deaths from maternal infectious and parasitic diseases, 30 I I deaths from all chronic conditions, 993 deaths from CVD, I 78 deaths from mental disorders, 191 deaths from respiratory diseases, 48 deaths from digestive diseases, 26 deaths from endocrine/ metabolic disorders, and 30 deaths from HIV (Table I). Maternal mortality from CVD increased sharply over time, from 0.40 per 100,000 live births deaths in 1999 to 1.82 in 2017 (Figure I). During 1999-2017, the average annual rate of increase in maternal mortality was $8.8 \%(95 \% \mathrm{Cl}=7.0 \%-$ $10.6 \%$ ) for CVD, II.3\% ( $95 \% \mathrm{Cl}=8.9 \%-13.7 \%$ ) for all chronic conditions combined, and $10.0 \%$ (95\% $\mathrm{Cl}=7.2 \%-\mathrm{I} 3.0 \%$ ) for infectious and parasitic diseases
(Figures I and 2). Trends from other causes are not shown because of small numbers of deaths.

\subsection{Inequalities in Maternal Mortality from Indirect Causes by Sociodemographic Factors}

During 2013-2017, mortality from indirect causes increased consistently with increasing maternal age, with relative risk of mortality being 17.9 times (76.76/4.28) higher for women aged $\geq 40$ years than for those aged $<20$ (Table 2). Non-Hispanic Blacks had $83 \%$ higher $(\mathrm{RR}=1.83$; $95 \% \mathrm{Cl}=1.60$ 2.06) and Hispanics $51 \%$ lower ( $R R=0.49 ; 95 \%$ $\mathrm{Cl}=0.4 \mathrm{I}-0.58)$ mortality from indirect causes than non-Hispanic Whites. Compared to APIs, nonHispanic Whites, non-Hispanic Blacks, and AIANs had 2.2 times higher ( $R R=2.22 ; 95 \% \mathrm{Cl}=\mathrm{I} .54-2.89)$, 4.I times higher ( $R R=4.06 ; 95 \% \quad C l=2.79-5.33)$, and 3.1 times higher $(R R=3.09 ; 95 \% \mathrm{Cl}=1.48-4.70)$ mortality from indirect causes, respectively.

Higher educational attainment was associated with lower maternal mortality from indirect causes. Non-Hispanic white women with $<12$ years of education had 4.4 times higher mortality than their counterparts with a college degree. Unmarried, USborn, and women in rural areas had $90 \%, 80 \%$, and $60 \%(R R=1.90,1.80,1.60)$ higher risks of maternal mortality from indirect causes than married, immigrant, and women in urban areas, respectively. Women in the southern region had 3.3 times higher mortality risk from indirect causes than those in the western region of the US.

Maternal mortality related to infectious diseases, including HIV, was 4 times greater among nonHispanic Black women than non-Hispanic White women (Table 2; data not shown). Compared to non-Hispanic White women, maternal mortality from all chronic conditions combined and from CVD was approximately two times higher among black women but $50 \%$ lower among Hispanics. The risk of maternal death due to poor mental health was similar in both non-Hispanic White and Black women but significantly higher compared with that for Hispanic women. Maternal mortality due to respiratory conditions was 2.9 times greater among non-Hispanic Black women than non-Hispanic White women. 


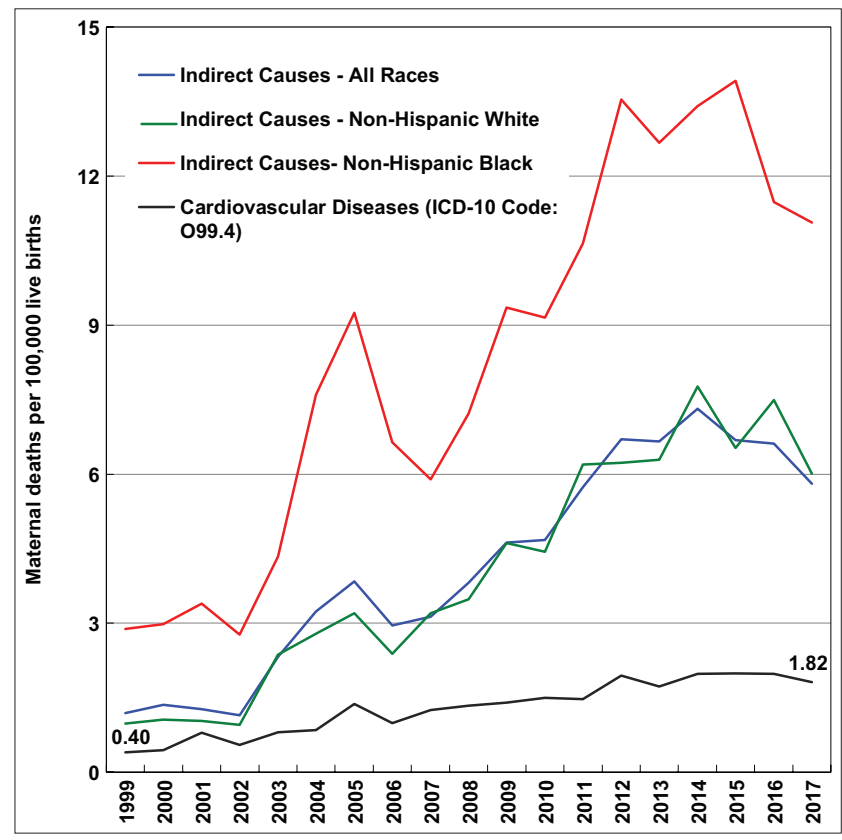

Figure I: Trends in maternal mortality from indirect obstetric causes (ICD-I0 Codes: O98-O99), United States, 1999-20I7 Source: Data derived from the National Vital Statistics System.

Table I: Maternal deaths and mortality rates per 100,000 live births due to specific indirect obstetric causes, (ICD- 10 codes: 098-099), United States, $1999-2017$ (number of live births =76,972,334)

\begin{tabular}{lcc}
\hline Cause of death (ICD-IO codes) & Maternal & Maternal \\
\cline { 2 - 3 } & Deaths & Mortality Rate \\
\hline All indirect causes (O98-O99) & 3,184 & 4.14 \\
\hline Maternal infectious and parasitic diseases (O98) & 173 & 0.22 \\
\hline Tuberculosis (O98.0) & 9 & $\mathrm{~N} / \mathrm{A}$ \\
\hline Syphilis, Gonorrhea, and other sexually transmitted infections (O98.1-O98.3) & 2 & $\mathrm{~N} / \mathrm{A}$ \\
\hline Viral hepatitis (O98.4) & 5 & $\mathrm{~N} / \mathrm{A}$ \\
\hline Other viral diseases (O98.5) & 12 & 0.02 \\
\hline Protozoal diseases (O98.6) & 0 & $\mathrm{~N} / \mathrm{A}$ \\
\hline HIV (O98.7) & 30 & 0.04 \\
\hline Other maternal infectious and parasitic diseases (O98.8) & 115 & 0.15 \\
\hline Unspecified maternal infectious and parasitic diseases (O98.9) & 0 & $\mathrm{~N} / \mathrm{A}$ \\
\hline Chronic diseases (O99) & 3,011 & 3.91 \\
\hline Anemia (O99.0) & 22 & 0.03 \\
\hline Blood \& immune disorders (O99.I) & 24 & 0.03 \\
\hline Endocrine and metabolic disorders (O99.2) & 26 & 0.03 \\
\hline Mental disorders and diseases of the nervous system (O99.3) & 178 & 0.23 \\
\hline Cardiovascular diseases (O99.4) & 993 & 1.29 \\
\hline Respiratory diseases (O99.5) & 191 & 0.25 \\
\hline Digestive system diseases (O99.6) & 48 & 0.06 \\
\hline Skin and subcutaneous disorders (O99.7) & 5 & $\mathrm{~N} / \mathrm{A}$ \\
\hline Other specified diseases and conditions (O99.8) & 1,524 & 1.98 \\
\hline Sur
\end{tabular}

Source: Derived from the National Mortality and Natality Detail Files, 1999-2017

Maternal mortality rates based on fewer than 10 deaths are not shown because of high variability associated with those rates. N/A $=$ not available 


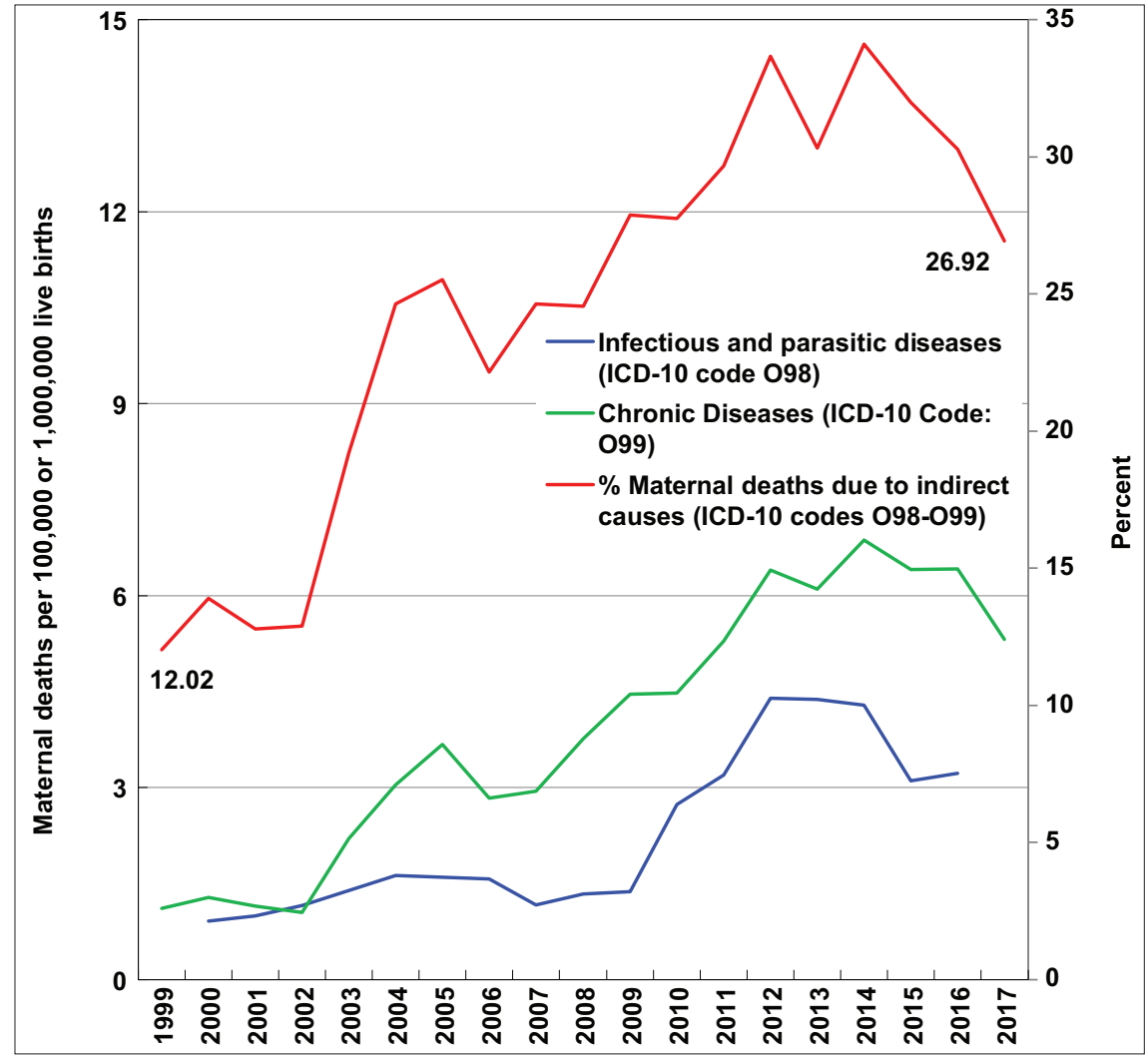

Figure 2: Trends in maternal mortality from infections (ICD-I0 code O98) and chronic diseases (ICD-I0 code O99), and proportion of all maternal deaths due to indirect obstetric causes (ICD-10 codes: O98-O99), United States, 1999-20I7

Source: Data derived from the National Vital Statistics System

Rates of maternal mortality from infections are three-year moving average rates and are per I,000,000 (million) live births. Rates of maternal mortality from chronic diseases are annual rates and are per 100,000 live births.

3.5. Inequalities in Maternal Mortality from Indirect Causes by Area Deprivation Index

During 2013-2017, women in the middle- and most-deprived area groups had 23\% ( $R R=1.23 ; 95 \%$ $\mathrm{Cl}=\mathrm{I} .03-\mathrm{I} .43)$ and $97 \%(\mathrm{RR}=1.97 ; 95 \% \mathrm{Cl}=1.63-$ 2.32) higher risks of maternal mortality from indirect causes than women in the most-affluent area group (Table 3). An approximately two-fold increased risk of maternal mortality from indirect causes was found among Non-Hispanic White and Black women living in the most-deprived areas (Table 3). When disparities across race/ethnicity and deprivation level were considered, maternal mortality rates from indirect causes varied greatly from 3.23 and 5.65 for Hispanics and non-Hispanic
Whites in the most affluent area-group to 14.45 per 100,000 for non-Hispanic Blacks in the most deprived area-group (a 4.5 -fold ethnic inequality). Patterns in maternal mortality by deprivation level were similar for all chronic conditions combined and for CVD, with women in the most deprived areagroup experiencing about twice the mortality risk of those in the most affluent area-group (Table 3).

\section{Discussion}

Using national vital statistics mortality data from 1999 to 2017, we found a rising trend in US maternal mortality from indirect causes, including CVD and all chronic conditions combined. The proportion of all maternal deaths due to indirect causes increased from $12.0 \%$ in 1999 to $26.9 \%$ in 2017 , with maternal 


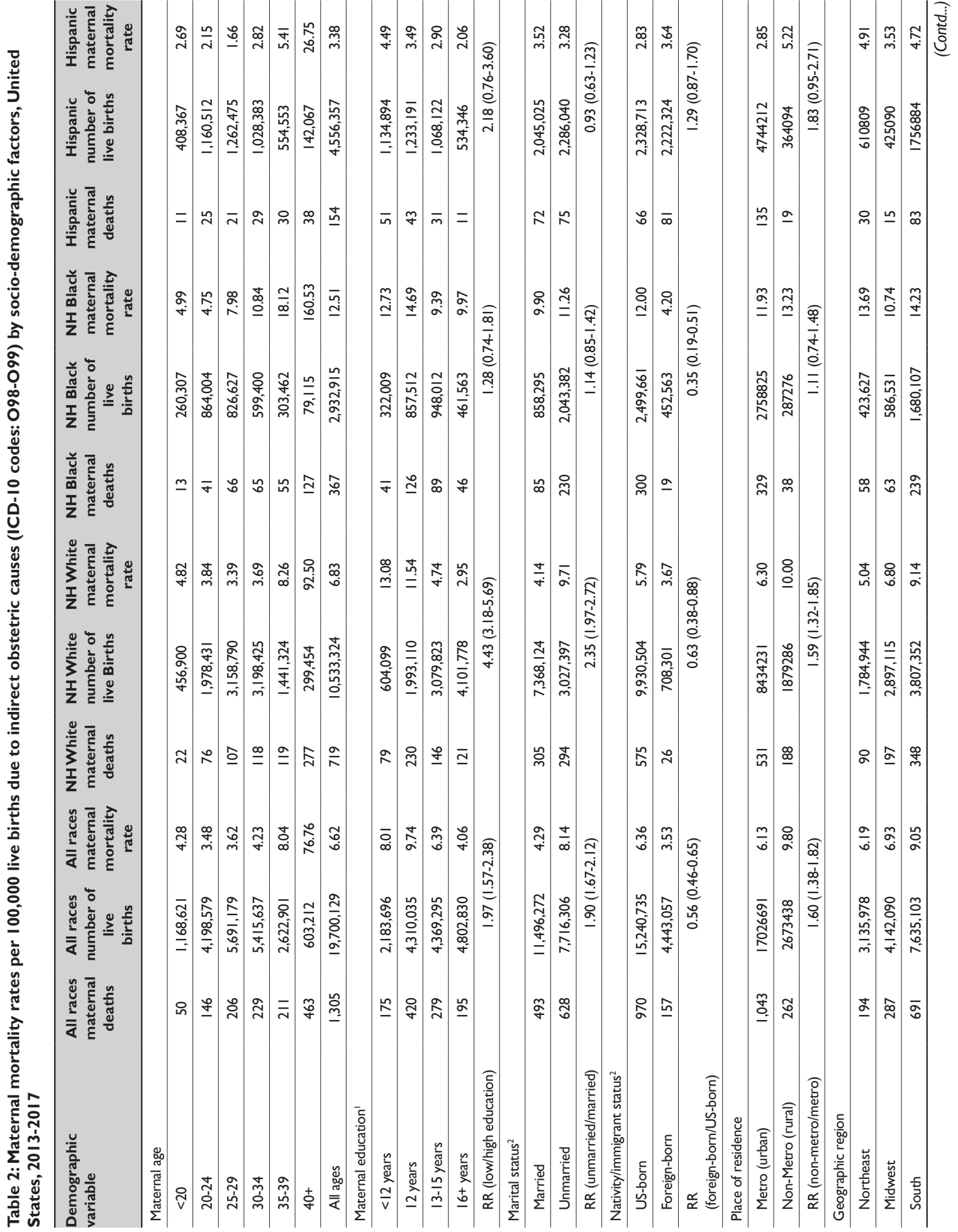

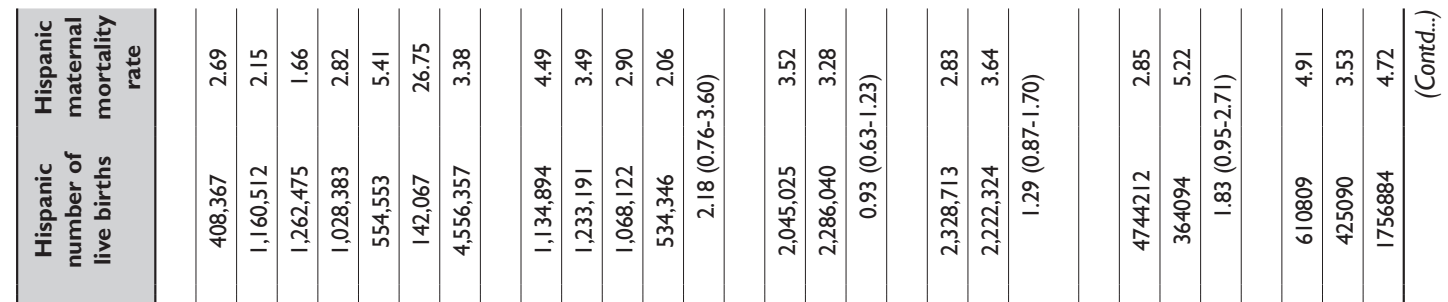

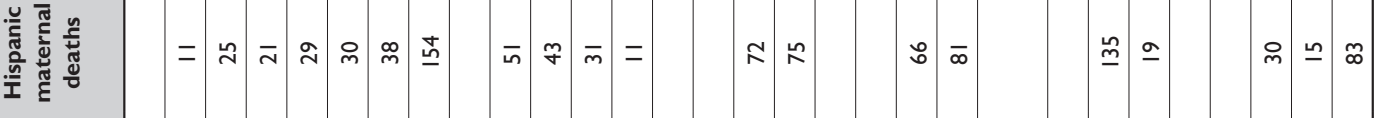

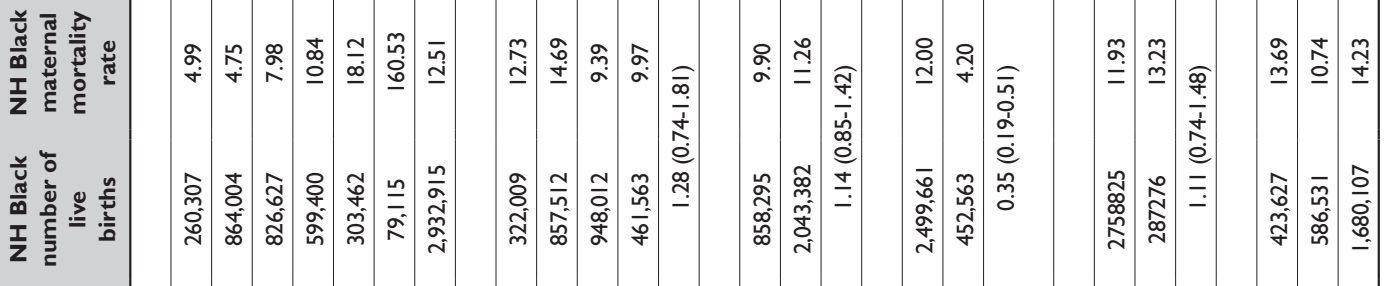

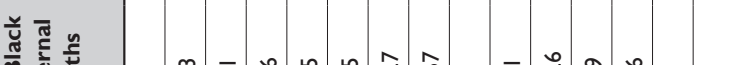




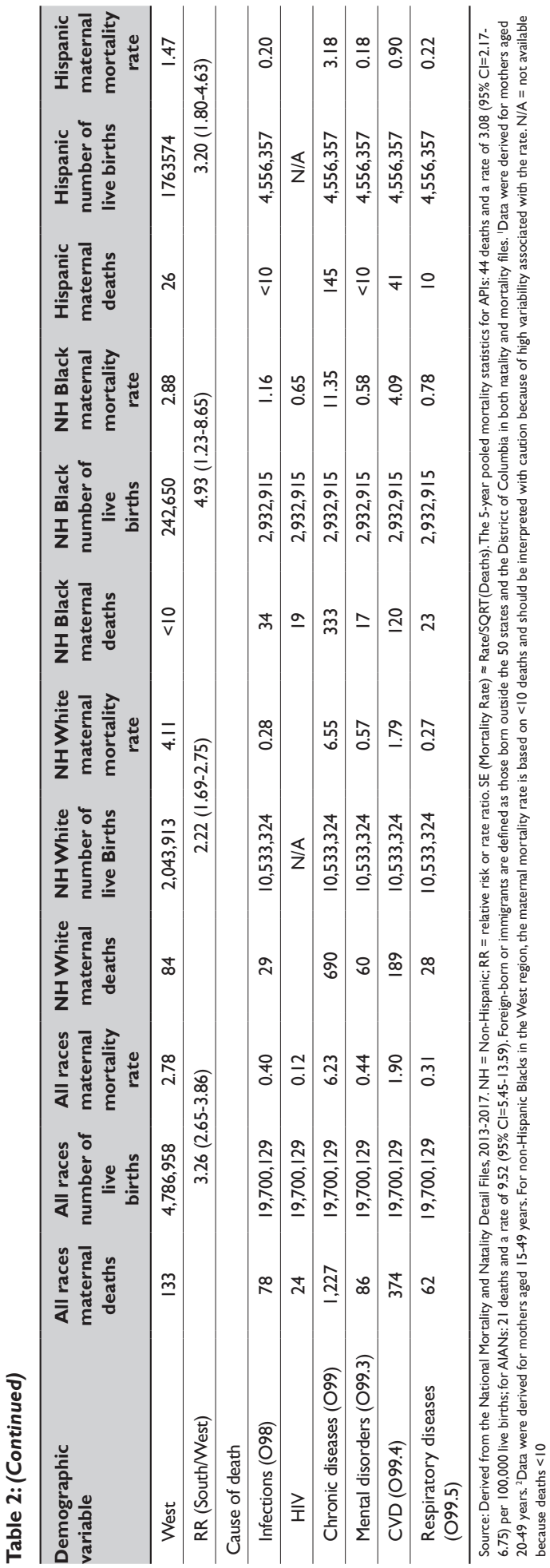

mortality from CVD increasing almost 5-fold during this time period. Our study shows marked disparities in maternal mortality from indirect causes by a wide array of social determinants, including maternal education, marital status, immigrant status, place of residence, geographic region, and area deprivation, which, although shown previously for overall maternal mortality and pregnancy-related mortality $8,9,16$, had not been documented for mortality from indirect causes to the best of our knowledge. Analysis of a broad range of disparities is important in showing the potential for reductions in US maternal mortality that can be achieved by implementing effective policies and interventions among high-risk groups and communities.

Efforts to reduce maternal mortality in the United States should be focused on indirect obstetric causes, in addition to addressing direct complications of pregnancy and childbirth. ${ }^{3,5,8,9}$ While maternal mortality from direct obstetric causes such as hemorrhage, pregnancy-related hypertension, and embolism has declined during the past two decades, maternal deaths due to indirect causes, particularly from pre-existing medical conditions, including CVD and metabolic disorders have risen. ${ }^{1-4,8,9}$ Given the increasing relative importance of indirect maternal causes of death, increased attention should be given to the healthcare needs of pregnant women with pre-existing conditions and high-risk pregnancies. ${ }^{5,17}$ Tackling the rising prevalence of obesity, diabetes, chronic hypertension, kidney diseases, and cardiovascular conditions among women of reproductive age should become a priority. 3,5

Trends and social inequalities in mortality from indirect causes reported here are generally consistent with those observed for maternal mortality overall (direct + indirect causes), pregnancy-related mortality, various risk factors, chronic medical conditions, and maternal complications including pre-pregnancy obesity, maternal diabetes, chronic hypertension, poor mental health, and cardiovascular conditions among women of reproductive age.8,9,16,18,19 For example, consistent with patterns in maternal mortality from indirect causes in our study, a recent study of the 2012-2014 US birth cohorts found that the risk of pre-pregnancy obesity was significantly higher among non-Hispanic Blacks, AIANs, non-Hispanic Whites, unmarried, US-born, women aged $\geq 35$, women with 
Table 3: Maternal deaths and mortality rates per 100,000 live births due to indirect obstetric causes (ICD-I 0 codes: 098-099) by Area Deprivation Index, United States, 20 I3-20 I 7 (number of live births $=19,699,940)$

\begin{tabular}{|c|c|c|c|c|c|}
\hline \multirow[t]{3}{*}{ Area deprivation Index } & \multirow{3}{*}{$\frac{\text { Maternal }}{\text { Deaths }}$} & \multirow{3}{*}{$\begin{array}{l}\text { Number of } \\
\text { Live Births }\end{array}$} & \multirow{3}{*}{$\begin{array}{c}\text { Maternal } \\
\text { Mortality } \\
\text { Rate }\end{array}$} & \multirow{3}{*}{$\begin{array}{c}\text { Maternal } \\
\text { Mortality } \\
\text { RR }\end{array}$} & \multirow[t]{3}{*}{$95 \% \mathrm{Cl}$} \\
\hline & & & & & \\
\hline & & & & & \\
\hline \multicolumn{6}{|c|}{ All indirect causes (ICD codes: O98-O99) } \\
\hline \multicolumn{6}{|l|}{ All races } \\
\hline $\mathrm{I}^{\text {st }}$ quintile (low SES) & 389 & $3,982,978$ & 9.77 & 1.97 & I.63-2.32 \\
\hline $2^{\text {nd }}-4$ th quintile (middle SES) & 730 & $11,959,599$ & 6.10 & 1.23 & $1.03-1.43$ \\
\hline $3^{\text {rd }}$ quintile (high SES) & 186 & $3,757,363$ & 4.95 & 1.00 & Reference \\
\hline \multicolumn{6}{|l|}{ Non-Hispanic White } \\
\hline It quintile (low SES) & 215 & $1,966,293$ & 10.93 & 1.93 & $1.50-2.37$ \\
\hline $2^{\text {nd }}-4^{\text {th }}$ quintile (middle SES) & 385 & $6,572,306$ & 5.86 & 1.04 & $0.82-1.25$ \\
\hline $3^{\text {rd }}$ quintile (high SES) & 119 & $2,105,188$ & 5.65 & 1.00 & Reference \\
\hline \multicolumn{6}{|l|}{ Non-Hispanic Black } \\
\hline It quintile (low SES) & 115 & 796,033 & 14.45 & 1.82 & $1.10-2.54$ \\
\hline $2^{\text {nd }}-4^{\text {th }}$ quintile (middle SES) & 221 & $\mathrm{I}, 77 \mathrm{I}, 290$ & 12.48 & 1.57 & $0.98-2.16$ \\
\hline $3^{\text {rd }}$ quintile (high SES) & 31 & 389,812 & 7.95 & 1.00 & Reference \\
\hline \multicolumn{6}{|l|}{ Hispanic } \\
\hline It quintile (low SES) & 40 & $\mathrm{I}, 024,822$ & 3.90 & 1.21 & $0.60-1.82$ \\
\hline $2^{\text {nd }-4^{\text {th }} \text { quintile (middle SES) }}$ & 90 & $2,789,575$ & 3.23 & 1.00 & $0.55-1.45$ \\
\hline $3^{\text {rd }}$ quintile (high SES) & 24 & 741,950 & 3.23 & 1.00 & Reference \\
\hline \multicolumn{6}{|c|}{ All chronic diseases (ICD code: O99) } \\
\hline \multicolumn{6}{|l|}{ All races } \\
\hline Ist quintile (low SES) & 362 & $3,982,978$ & 9.09 & 1.91 & $1.57-2.25$ \\
\hline $2^{\text {nd }-4^{\text {th }} \text { quintile (middle SES) }}$ & 686 & II,959,599 & 5.74 & 1.21 & $1.01-1.40$ \\
\hline $3^{\text {rd }}$ quintile (high SES) & 179 & $3,757,363$ & 4.76 & 1.00 & Reference \\
\hline \multicolumn{6}{|l|}{ Non-Hispanic White } \\
\hline It $^{\text {st }}$ quintile (low SES) & 202 & $1,966,293$ & 10.27 & 1.83 & $1.41-2.25$ \\
\hline $2^{\text {nd }}-4^{\text {th }}$ quintile (middle SES) & 370 & $6,572,306$ & 5.63 & 1.00 & $0.80-1.21$ \\
\hline $3^{\text {rd }}$ quintile (high SES) & 118 & $2,105,188$ & 5.61 & 1.00 & Reference \\
\hline \multicolumn{6}{|l|}{ Non-Hispanic Black } \\
\hline It quintile (low SES) & 106 & 796,033 & 13.32 & 2.00 & $1.14-2.85$ \\
\hline $2^{\text {nd }}-4^{\text {th }}$ quintile (middle SES) & 201 & $\mathrm{I}, 77 \mathrm{I}, 290$ & 11.35 & 1.70 & $1.01-2.40$ \\
\hline $3^{\text {rd }}$ quintile (high SES) & 26 & 389,812 & 6.67 & 1.00 & Reference \\
\hline \multicolumn{6}{|l|}{ Hispanic } \\
\hline It quintile (low SES) & 38 & $\mathrm{I}, 024,822$ & 3.71 & 1.15 & $0.56-1.74$ \\
\hline $2^{\text {nd }}-4^{\text {th }}$ quintile (middle SES) & 83 & $2,789,575$ & 2.98 & 0.92 & $0.50-1.34$ \\
\hline $3^{\text {rd }}$ quintile (high SES) & 24 & 741,950 & 3.23 & 1.00 & Reference \\
\hline
\end{tabular}


Table 3: (Continued)

\begin{tabular}{|c|c|c|c|c|c|}
\hline \multirow[t]{3}{*}{ Area deprivation Index } & \multirow{3}{*}{$\frac{\text { Maternal }}{\text { Deaths }}$} & \multirow{3}{*}{$\begin{array}{l}\text { Number of } \\
\text { Live Births }\end{array}$} & \multirow{3}{*}{$\begin{array}{c}\text { Maternal } \\
\text { Mortality } \\
\text { Rate }\end{array}$} & \multirow{3}{*}{$\begin{array}{c}\text { Maternal } \\
\text { Mortality } \\
\text { RR }\end{array}$} & \multirow[t]{3}{*}{$95 \% \mathrm{Cl}$} \\
\hline & & & & & \\
\hline & & & & & \\
\hline \multicolumn{6}{|c|}{ Cardiovascular diseases (ICD code: O99.4) } \\
\hline \multicolumn{6}{|l|}{ All races } \\
\hline It quintile (low SES) & 108 & $3,982,978$ & 2.71 & 2.17 & $1.57-2.38$ \\
\hline $2^{\text {nd }}-4^{\text {th }}$ quintile (middle SES) & 219 & II,959,599 & 1.83 & 1.46 & $1.57-2.38$ \\
\hline $3^{\text {rd }}$ quintile (high SES) & 47 & $3,757,363$ & 1.25 & 1.00 & Reference \\
\hline \multicolumn{6}{|l|}{ Non-Hispanic White } \\
\hline Ist $^{\text {suintile (low SES) }}$ & 51 & $1,966,293$ & 2.59 & 1.76 & $0.98-2.55$ \\
\hline $2^{\text {nd }}-4^{\text {th }}$ quintile (middle SES) & 107 & $6,572,306$ & 1.63 & I.II & $0.67-1.55$ \\
\hline $3^{\text {rd }}$ quintile (high SES) & 31 & $2,105,188$ & 1.47 & 1.00 & Reference \\
\hline \multicolumn{6}{|l|}{ Non-Hispanic Black } \\
\hline It quintile (low SES) & 38 & 796,033 & 4.77 & 2.06 & $0.56-3.57$ \\
\hline $2^{\text {nd }}-4^{\text {th }}$ quintile (middle SES) & 73 & I,77I,290 & 4.12 & 1.78 & $0.55-3.02$ \\
\hline $3^{\text {rd }}$ quintile (high SES) & $<10$ & 389,812 & 2.31 & 1.00 & Reference \\
\hline
\end{tabular}

less education, and rural residents..$^{20}$ Mothers with less than a high school or with a high school diploma had more than twice the risk of pre-pregnancy obesity than those with a college degree, and USborn women had $59 \%$ higher risk than immigrant women $^{20}$ - estimates similar to those reported in our study on maternal mortality from indirect causes.

Another recent US study showed marked disparities in maternal hypertension (consisting of both chronic hypertension and pregnancy-related hypertension) by various social determinants. ${ }^{19}$ AIANs, non-Hispanic Blacks, and Pacific Islanders had higher risks of maternal hypertension and chronic hypertension, whereas Asians, Hispanics, and non-Hispanic Whites had lower risks of maternal hypertension, including chronic hypertension. ${ }^{19}$ Increasing maternal age, lower education, US-born status, rural residence, prepregnancy obesity, excess weight gain during pregnancy, and gestational diabetes were all associated with increased risks of maternal hypertension. ${ }^{19}$ In addition, smoking before and during pregnancy was associated with significantly increased risk of chronic hypertension. ${ }^{19}$
Data on women of reproductive age (18-49 years) from the 20I0-20I4 US National Health Interview Survey indicate markedly higher prevalence of CVD, hypertension, diabetes, kidney disease, asthma, and serious psychological distress among non-Hispanic Black and AIAN women, women at older ages, those at lower education and income levels, unmarried (divorced/separated/ never married) women, US-born women, current smokers, and women with obesity. ${ }^{18,19}$ Ethnicminority and socially-disadvantaged groups in the US differ greatly from the majority, affluent groups in their social, physical, and living environments that might influence pre-existing chronic and medical conditions and related risks such as prepregnancy obesity, smoking, gestational diabetes, pregnancy-related hypertension, and weight gain during pregnancy. ${ }^{19}$ They have limited access to neighborhood amenities such as sidewalks, parks/ playgrounds, green spaces, public transportation, and heathy, affordable foods that promote physical activity, healthy lifestyle, and healthy living. ${ }^{19,21}$ Many of the risk factors identified above are modifiable, and maternal deaths from most of the indirect causes are largely preventable. Several community- 
based federal programs have been successful in reducing rates of obesity, physical inactivity, smoking, and chronic hypertension and promoting healthy eating and weight management. ${ }^{19-21}$

\section{I. Limitations}

This study has limitations. Underreporting of mortality statistics for Hispanics, APIs, and AIANs on the death certificate may lead to an underestimation of maternal mortality rates for these racial/ethnic groups. ${ }^{1,10}$ Inconsistencies in the reporting of race/ ethnicity, educational attainment, marital status, nativity status, and maternal age in numerator (deaths) and denominator (births) databases may lead to misestimation of maternal mortality rates. ${ }^{1,10,11}$ Because of the small numbers of deaths, our analysis does not show the full extent of racial/ ethnic disparities in maternal mortality from indirect causes as overall maternal mortality rates among API and Hispanic subgroups have been shown to vary greatly, with Filipinos and Puerto Ricans, for example, at substantially higher risks of maternal mortality than Chinese, Asian Indians, and Central/ South Americans. ${ }^{16}$

Another limitation refers to the fact that data used in this study come from two different unlinked data sources: national mortality and national natality databases. The natality database was only used to derive the total number of births overall and by social determinants, which were used as denominators to compute maternal mortality rates. This differs from the CDC's Pregnancy Mortality Surveillance System that links pregnancy-related deaths up to one year to corresponding cohorts of live births and fetal deaths, which allows one to analyze severe maternal morbidity (SMM) outcomes such as hypertensive disorders in pregnancy, eclampsia, obstetric infections, hemorrhage, embolism, uterine rupture, and other pregnancy complications and their impacts on maternal mortality. 8 .9 Because of the unlinked nature of our data sources, we were unable to carry out detailed individual-level analyses of maternal mortality that are typical of SMM studies. Lastly, the differential adoption of a pregnancy checkbox item on the death certificate by many states may have been a factor influencing the recent trend (or apparent increase or misclassification) in maternal deaths and mortality from indirect causes. ${ }^{1,9,10,16,22,23}$

\section{Conclusions and Global Health Implications}

While US maternal mortality from direct obstetric causes has declined during the past two decades, maternal deaths due to indirect causes, particularly from pre-existing medical conditions, including CVD, have increased. ${ }^{1,9,10,16}$ As is the case with overall maternal mortality ${ }^{16}$, socially and economically-disadvantaged demographic groups and communities experience 2-to-6 times higher risk of maternal mortality from indirect causes. There is a growing understanding that the contribution of indirect causes is misclassified and underestimated., ${ }^{5,17}$ Pre-pregnancy obesity, for example, increases the risk of both direct and indirect causes of maternal mortality, including chronic and gestational diabetes, pregnancyrelated hypertension, pre-eclampsia and eclampsia, spontaneous abortion, hemorrhage, and uterine rupture. ${ }^{17,19}$ Yet, obesity is only considered an indirect or contributing condition rather than an underlying cause of maternal death. ${ }^{17}$ Monitoring social inequalities is important in that they represent the impact of underlying social determinants on both indirect and direct causes of maternal mortality. ${ }^{4,24}$ Understanding the complex interactions among social determinants, indirect causes, and more proximal direct causes of maternal deaths is important to reducing maternal mortality and improving maternal health. ${ }^{5,17}$

\section{Compliance with Ethical Standards}

Conflicts of Interest: None. Financial Disclosure: None to report. Funding/Support: Dr. Hyunjung Lee was supported in part by an appointment to the Research Participation Program at the Health Resources \& Services Administration - Office of Health Equity (HRSA-OHE), administered by the Oak Ridge Institute for Science and Education (ORISE) through an interagency agreement between the US Department of Energy and HRSA. Ethical approval: No IRB approval was required for this study, which is based on the secondary analysis of public-use federal databases. Disclaimer: The views expressed are the authors' and not necessarily those of the Health Resources and Services Administration or the US Department of Health and Human Services. 


\section{Key Messages}

During 1999-2017, maternal mortality rates due to indirect obstetric causes and pre-existing chronic conditions increased annually by $1 \mathrm{I} .2 \%$ for the overall population, $12.9 \%$ for non-Hispanic Whites, and $9.4 \%$ for non-Hispanic Blacks.

The proportion of all maternal deaths due to indirect causes increased from $12.0 \%$ in 1999 to $26.9 \%$ in 2017 . Maternal mortality from CVD increased 4.6-fold during 1999-2017.

Social determinants were strongly linked to maternal mortality from indirect causes. Non-Hispanic White women without a high school diploma had 4.4 times higher mortality than their counterparts with a college degree. Unmarried, US-born, and women living in rural and deprived areas had 1.6-2.0 times higher risk of maternal mortality than married, immigrant, and women in urban and affluent areas, respectively.

Maternal mortality from infectious diseases, including HIV, was 4.I times greater, from CVD 2.3 times greater, and from respiratory diseases 2.9 greater among non-Hispanic Black women compared to non-Hispanic White women. Understanding complex interactions among social determinants, indirect causes (pre-existing medical conditions (e.g., CVD, diabetes, respiratory disorders, and mental disease), and proximate direct causes (e.g., hemorrhage, pregnancy-related hypertension, and embolism) is important to reducing maternal mortality and improving maternal health.

\section{References}

I. Kochanek KD, Murphy SL, Xu JQ,Arias E. Deaths: final data for 2017. Natl Vital Stat Rep. 2019;68(9): I-77.

2. National Center for Health Statistics. National Vital Statistics System, Mortality Multiple Cause-of-Death Public Use Data File Documentation. Hyattsville, MD: US Department of Health and Human Services; 2019. http:// www.cdc.gov/nchs/nvss/mortality_public_use_data.htm. Accessed 23 September, 2020.

3. Kassebaum NJ, Bertozzi-Villa A, Coggeshall MS, et al. Global, regional, and national levels and causes of maternal mortality during 1990-2013: a systematic analysis for the Global Burden of Disease Study 2013. Lancet. 2014; 384(9947):980-1004.

4. Say L, Chou D, Gemmill A, et al. Global causes of maternal death: a WHO systematic analysis. Lancet Global Health. 20।4; 2(6):e323-e333.

5. Storm F, Agampadi S, Eddelston M, et al. Indirect causes of maternal death. Lancet Global Health. 20 14; 2(10):e566.

6. Joseph KS, Lisonkova S, Muraca GM, et al. Factors underlying the temporal increase in in maternal mortality in the United States. Obstet Gynecol. 2017; 129(1):91-100.

7. MacDorman MF, Declercq E,Thoma ME.Trends in maternal mortality by socio-demographic characteristics and cause of death in 27 states and the District of Columbia. Obstet Gynecol. 2017; 129(5):81 I-818.

8. Petersen EL, Goodman D, Cox S, et al. Racial/ethnic disparities in pregnancy-related deaths - United States, 2007-2016. MMWR. 2019; 68(35):762-765.

9. Berg CJ, Callaghan WM, Syverson C, Henderson Z. Pregnancy-related mortality in the United States, 1998 to 2005. Obstet Gynecol. 201 0; I I6(6): I 302- I 309.

10. Xu JQ, Kochanek KD, Murphy SL, Tejada-Vera B. Deaths: final data for 2007. Nat/ Vital Stat Rep. 20 10;58(I 9): I- 135.

I I. Martin JA, Hamilton BE, Osterman MJK, Driscoll AK, Drake P. Births: final data for 2017. Nat/Vital Stat Rep. 20 I8;67(8): I-50.

12. Singh GK, Azuine RE, Siahpush M, Kogan MD.All-cause and cause-specific mortality among US youth: socioeconomic and rural-urban disparities and international patterns. J Urban Health. 201 3; 90(3):388-405.

13. Singh GK. Area deprivation and widening inequalities in US mortality, I 969- | 998. Am J Public Health. 2003; 93(7): I I 37- I | 43.

14. Singh GK, Siahpush M. Increasing inequalities in all-cause and cardiovascular mortality among US adults aged 2564 years by area socioeconomic status, 1969-1998. Int J Epidemiol. 2002; 3 I (3):600-6I3.

15. Singh GK, Jemal A. Socioeconomic and racial/ethnic disparities in cancer mortality, incidence, and survival in the United States, 1950-20 I4: over six decades of changing patterns and widening Inequalities. J Environ Public Health. DOI: 2017/2819372. Epub March 2017.

16. Singh GK. Trends and social inequalities in maternal mortality in the United States, 1969-20 I8. Int J MCH AIDS. 2021;10(I):29-42.

17. van den Akker, Nair M, Geodhart M, et al. Maternal mortality: direct or indirect has become irrelevant. Lancet Global Health. 2017; 5(I2):el I8I3.

18. National Center for Health Statistics. The National Health Interview Survey, Questionnaires, Datasets, and Related Documentation: 2010-2014 Public Use Data Files. Hyattsville, MD: US Department of Health and Human 
Services; 2015. http://www.cdc.gov/nchs/nhis/nhis_ questionnaires.htm. Accessed 23 September, 2020.

19. Singh GK, Siahpush M, Liu L, Allender M. Racial/Ethnic, nativity, and sociodemographic disparities in maternal hypertension in the United States, 2014-2015. Int J Hypertens. 2018 May I7; DOI: 10.1 I55/2018/7897I89.

20. Singh GK, DiBari JN. Marked disparities in prepregnancy obesity and overweight prevalence among US women by race/Ethnicity, nativity/immigrant status, and sociodemographic characteristics, 2012-2014.J Obes. 2019 February. DOI: I0.II55/2019/2419263.

21. Singh GK, Siahpush M, Kogan MD. Neighborhood Socioeconomic Conditions, Built Environments, and Childhood Obesity. Health Aff. 2010;29(3):503-5I 2.

22. Hoyert DL, Uddin SFG, Miniño AM. Evaluation of the pregnancy status checkbox on the identification of maternal deaths. Natl Vital Stat Rep. 2020;69(I): I-25.

23. Hoyert DL, Miniño, AM. Maternal mortality in the United States: changes in coding, publication, and data release, 2018. Natl Vital Stat Rep. 2020;69(2): I - I8.

24. Jolivet RR, Moran AC, O'Connor M, Chou D, Bhardwaj N,
Newby $\mathrm{H}$, et al. Ending preventable maternal mortality: phase II of a multi-step process to develop a monitoring framework, 2016-2030. BMC Pregnancy Childbirth. 2018; I8(I):258. https://doi.org/I0.I I86/s I 2884-0I8-I763-8. Accessed 23 September, 2020.

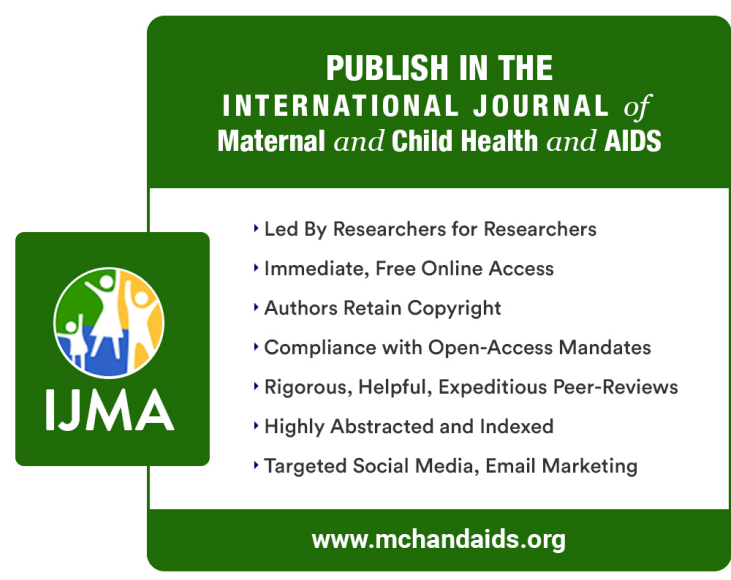

